\title{
VARIA
}

\author{
EL HALLAZGO DE LOS FRESCOS DE PAOLO DE SAN LEOCADIO \\ EN LA CATEDRAL DE VALENCIA Y ALGUNAS CONSIDERACIONES \\ ACERCA DE FRANCESCO PAGANO *
}

El extraordinario acontecimiento del hallazgo de frescos de la época del Renacimiento bajo las estructuras barrocas que revisten la bóveda de la Capilla Mayor de la Catedral de Valencia, que tuvo lugar el 20 de junio de 2004, pone de actualidad un argumento que traté el año pasado, en Palermo, con ocasión del Convenio internacional sobre Antonello y la pintura del Quattrocento en la Europa mediterránea ${ }^{1}$.

El argumento de mi citada intervención versaba, entre otros temas, sobre la personalidad de Francesco Pagano, llevado a Valencia en 1472, junto con Paolo de San Leocadio, por el cardenal Rodrigo de Borja, para que pintase al fresco las paredes y la bóveda de la Capilla Mayor de la Catedral, cuyo decorado medieval había sido destruido, el 21 de mayo de 1469, por un devastador incendio. El desastre había sido provocado por una paloma de plata, la palometa, que ondulando, suspendida de la bóveda del ábside, dejaba caer el día de Pentecostés, según un antiguo rito, una lluvia de ascuas encendidas que simulaban el descenso del Espíritu Santo. Desgraciadamente una de estas ascuas cayó tras el guardapolvo del retablo de plata y, al rescoldo del polvo acumulado de siglos, se transformó en un fuego imponente que destruyó el retablo y los frescos medievales. Éstos fueron substituidos en el decenio sucesivo por los del Renacimiento, obra de los dos maestros italianos ${ }^{2}$. Pero la mala suerte continuaba a perseguir los decorados de la Capilla Mayor, la cual, en el s. XVII, fue completamente renovada y, en aquel momento, no se tuvo reparo en sacrificar los frescos del Renacimiento, que desaparecieron bajo la decoración barroca.

Sin embargo, por una curiosa y sugestiva coincidencia, otra vez las palomas han tenido un papel relevante en la cuestión de los frescos de la Capilla Mayor. A distancia de cinco siglos, ha sido precisamente el revoloteo de las palomas, que desde hacía tiempo penetraban en la catedral a través de un agujero que habían hecho en la bóveda del ábside, una de las causas de la puesta en marcha de los trabajos de restauración de la cúpula, haciendo así posible el hallazgo de los frescos del s. xv, hasta entonces tenidos por irremediablemente perdidos. De esta

\footnotetext{
${ }^{*}$ Agradezco al Profesor, Dr. Juan Nadal y Cañellas, la gentileza de haberme traducido este artículo del italiano al castellano.

${ }^{1}$ Adele Condorelli, Problemi di pittura valenzana. Il maestro Riquart e Francesco Pagano, en Antonello e la pittura del Quattrocento nell'Europa Mediterranea, Atti del seminario internazionale, Palermo 10-11 de octubre de 2003 (en prensa).

${ }^{2}$ Adele Condorelli, La leyenda del «Mestre» Riquart y de Ricardo Quartararo, en «Archivo Español de Arte» LXXIV, 2001, pp. 285-291.
} 
manera, la palometa de Pentecostés ha encontrado el modo de hacerse perdonar su antigua, aunque involuntaria, culpa.

En el crucero de la bóveda han salido a la luz los ángeles músicos que, personificando el coro de alabanza del Salmo CL, forman corona sobre la Majestad Divina, ésta irremediablemente perdida, pintados por Paolo de San Leocadio, como se deduce de los documentos existentes en el Archivo de la Catedral, atribución documental que, por si hiciera falta, se ve corroborada por el estilo del pintor emiliano. He tenido la suerte de poder admirar el concierto de los ángeles de Paolo da San Leocadio en la Catedral de Valencia a través de numerosos orificios que, desafortunadamente, no permiten una visión global del conjunto. A pesar de esto, he experimentado una intensa emoción: contemplaba, incrédula, lo que durante muchísimos años había vagamente imaginado, gracias a la descripciones contenidas en los documentos. Me ha impresionado la monumentalidad de los ángeles músicos con su espléndido color original, fluctuantes al viento que hincha sus vestidos y hace ondear sus cabelleras, de la atrevida escenografía de Paolo, que revela influencias de Mantegna, recibida a través de Franesco del Cossa, sin hablar de su dominio absoluto del dibujo, de la perspectiva, del color y de la técnica del fresco. Cuando el concierto de los ángeles, debidamente restaurado, vuelva a resplandecer en la bóveda de la Capilla Mayor, la Catedral de Valencia habrá adquirido de nuevo una obra maestra, digno remate de las espléndidas puertas del retablo de plata pintadas por Ferrando Llanos y Ferrando Yañez de la Almedina.

Como se verá a continuación, Francesco Pagano no intervino en manera alguna en la ejecución de los frescos de la bóveda de la Capilla Mayor, conclusión ésta derivada de la atenta lectura de los documentos que han llegado hasta nosotros, que nos permiten, además, trazar un breve perfil del maestro napolitano.

De los dos pintores que llevó a Valencia Rodrigo de Borja, Francesco Pagano, siendo el más anciano, había asumido el papel de jefe de la empresa, ejerciendo su autoridad sobre el joven Paolo de San Leocadio quien, en 1472, tenía veinticinco años, pues había nacido en Reggio Emilia en 1447. El dinero que correspondía a entrambos era entregado al maestro napolitano, quien lo guardaba celosamente en una caja depositada en la sacristía de la catedral. Es preciso señalar que, pese a su joven edad, Paolo no era un subalterno de Francesco, sino un Señor pintor, como se le define en los documentos, en paridad de méritos con su anciano compañero.

Siempre me he preguntado cuál fue el criterio adoptado por Rodrigo de Borja para escoger esta extraña pareja de pintores, uno napolitano y otro emiliano, tan diversos entre ellos por origen, cultura, edad y temperamento.

En un escrito mío en honor de Alessandro Marabottini ${ }^{3}$ he sugerido la hipótesis de que Paolo de San Leocadio pudiese haber sido presentado al cardenal por Vannozza Cattanei, que fue luego la madre de sus hijos predilectos: César, Juan, Lucrecia y Joffré. Vannozza, de origen mantuano, o tal vez bresciano, era hija de un pintor que se llamaba Jacopo y sobrina de Antonio da Brescia, el escultor que, desde 1468, esculpía a la manera «lombarda» para el papa Barbo, gran amigo de Rodrigo de Borja, los mármoles del Palacio de Venecia. Antonio era uno de los más grandes representantes de aquel nutrido grupo de maestros lombardos venidos del norte para trabajar en aquel gran complejo urbanístico que era la Roma papal de la segunda mitad del s. Xv.

Es verosímil que el joven emilano hubiese llegado a Roma en 1471 en el sequito de Borso d'Este, quien, encabezando una gran comitiva, marchó aquel año de Ferrara a Roma para recibir de Paulo II la investidura ducal. En Roma, Paolo debió formar parte del grupo de artistas

\footnotetext{
${ }^{3}$ Adele Condorelli, Una nuova attribuzione a Fernando de Llanos e un 'ritrovato' Cristo Portacroce di Paolo di San Leocadio, en Scritti in onore di Alessandro Marabottini, Roma, 1997, pp. 103-110.
}

AEA, LXXVIII, 2005, 310, pp. 175 a 201 
lombardos que giraba en torno a la familia de Vannozza, que les procuraba asistencia y trabajo. Gracias a los buenos oficios de Vannozza Cattanei, podría haber obtenido la alta protección de cardenal y, a continuación, los innumerables privilegios que le concedió la duquesa María Enríquez, viuda de Juan de Borja y nuera de Vannozza y de Rodrigo, la cual, en el primer decenio del s. xvi, quiso tenerlo a su servicio en el palacio ducal de Gandía, otorgándole incluso el alto honor de ser la madrina de sus hijas.

El estilo de Paolo, de quien se conservan obras documentadas y firmadas, revela su formación paduano-ferrarense. Con toda probabilidad, en Ferrara, en el gran salón de Schifanoia, ayudando a Francesco del Cossa, que trabajaba para Borso d'Este, Señor de Ferrara, Modena y Reggio Emilia, Paolo aprendió la técnica del fresco y a pintar figuras. Supongo que éste fue el principal motivo por el cual fue contratado por el cardenal, en busca de buenos pintores del fresco para la Catedral valenciana.

Si para Paolo yo había encontrado una posible vinculación con Rodrigo de Borja, para Francesco Pagano, que siempre se declaraba 'napolitano', no llegaba a individuar un nexo que pudiese relacionarlo con el cardenal, porque partía de la errónea suposición de que habitase Nápoles y que, en 1472, se hubiese encontrado en Roma por una casualidad fortuita, como había sucedido en el caso del emiliano Paolo de San Leocadio. La solución del problema se encuentra, sin embargo, entre las líneas de un documento publicado por Sanchis y Sivera en Pintores medievales en Valencia ${ }^{4}$. Se trata de un testamento que Francesco Pagano hizo el 25 de junio de 1476. Estando gravemente enfermo y creyéndose a punto de morir, dictó sus últimas voluntades.

Su testamento comienza con las siguientes palabras: yo francisco pagano, napolitano, habitan en Roma e de present en la ciutat de Valencia, pintor al fresch, ... Francesco Pagano residía por tanto en Roma y no en Nápoles, ejercitando el arte de la pintura al fresco, como él mismo declara. Surgió entonces inmediatamente en mi mente el recuerdo de los frescos que se supone habían cubierto las bóvedas de todos los salones del palacio romano de Rodrigo de Borja y, sobre todo, de la famosa cámara de las estrellas, decorada con la representación de los planetas, de la cual resta solamente el recuerdo. Es verosímil que el autor de la admirable decoración al fresco del palacio de la vieja cancelería, que tanta admiración suscitaba en los visitantes, hubiese sido precisamente Francesco Pagano y por este motivo el cardenal, considerándolo perfectamente idóneo para el delicado encargo de pintar al fresco la Capilla Mayor de la Catedral, lo llevó a Valencia.

Rodrigo de Borja, sin embargo, conocía bien los límites de su pintor, magnífico decorador que, con sabia técnica, hacía brillar las estrellas de oro de ley sobre el fondo azul de Acre y de Alemania, que componía ricos festones de flores y frutas sobre fingidos cortinajes, pero que se habría encontrado con serias dificultades para pintar las figuras. Creo que ésta fue la razón que llevó al cardenal a colocar a su lado al joven Paolo de San Leocadio, hábil pintor de figuras. Según una costumbre entonces vigente, que se mantuvo en los siglos sucesivos, Rodrigo de Borja escogió un pintor de decoraciones y un pintor de figuras para adornar el ábside de la Catedral de Valencia.

Esto es lo que se deduce de los documentos publicados por Sanchis y Sivera. En el citado testamento, Francesco Pagano, creyendo que iba a morir, confiesa deber a su compañero doscientos ducados, y ordena a los albaceas testamentarios que los saquen de su caja, la que se guardaba en la sacristía de la Catedral, para darlos a Paolo de San Leocadio. Sin embargo, Francesco, habiéndose restablecido, no mantuvo su resolución y sucedió que, dos meses después de la redacción del testamento, el airado Paolo le obligó a sacar de la famosa caja los

${ }^{4}$ José Sanchís y Sivera, Pintores medievales en Valencia, Valencia, 1930, pp. 180-182.

$A E A$, LXXVIII, 2005, 310, pp. 175 a 201 
doscientos ducados que le pertenecían. Las relaciones entre los dos pintores se fueron haciendo cada vez más tensas y se multiplicaron sin cesar las disputas por causa del dinero que Francesco Pagano cobraba y no repartía en la justa medida con su compañero. Además, Francesco debía vanagloriarse de realizar la mayor parte de los frescos que, en realidad, pintaba Paolo, como se deduce del documento del 23 de septiembre de 1476. El canónigo Sanchis y Sivera comenta que el documento que transcribe es muy curioso y demuestra que era Francesco Pagano el que ganaba la mayor parte del dinero, aunque no fuese él quien más trabajaba, quizás, añade, porque era el más viejo o por causa de su reciente enfermedad.

Leemos aún en el documento ${ }^{5}$ que para poner fin a las continuas disputas: fonch concordat e pactat entre los dits pintors per fugir a tot escandel e inconvenient entre los dits pintors, que si poria que lo mestre Francisco pinte e obre los capitells e tota la part jusana sota aquells segons forma dels capitols e lo dit mestre paulo pintara e acabara la part de munt dels dits capitells, ço es, los apostols e la maiestat e los seraphins e altres coses necessaries a la dita pintu$r a$. De esta manera Francisco no podría mentir y queda bien definido el cometido y las competencias de cada uno de los pintores: Francesco Pagano, pintor de decorados, deberá ejecutar los frescos ornamentales de la parte subyacente a los capiteles que delimitan la bóveda del ábside, mientras que a Paolo de San Leocadio, pintor de figuras, tocará el quehacer más arduo y comprometido de representar, en la parte alta, la Majestad Divina rodeada de ángeles y santos.

A partir de 1481 no tenemos más noticias de Francesco Pagano. Acabado el trabajo de la Catedral, y siendo un pintor experto solamente en la decoración al fresco, no habría encontrado en Valencia otros encargos. Por su testamento sabemos que Francesco Pagano no tenía familia y, siendo ya de edad avanzada y de salud precaria, si no murió en Valencia, tal vez regresó a Italia, pero, en este caso, en lugar de ir a Nápoles, es más lógico suponer que se hubiese refugiado en Roma, donde habitaba antes de ir a Valencia, poniéndose de nuevo bajo la alta protección del cardenal Rodrigo de Borja, su generoso mecenas, el único tal vez que todavía era capaz de ayudarle.

En Valencia, de la obra de Francesco Pagano, no queda nada, si se excluye el fragmento del fresco de prueba, que representa la Natividad, en la Sala Capitular. Pero el rostro de la Virgen, de evidente porte ferrarense, se debe ciertamente a la mano de Paolo de San Leocadio y, si damos fe a los documentos, suponemos que, en este fresco, la cooperación del maestro napolitano fue absolutamente marginal. Por otra parte, por lo que atañe a los frescos de la Capilla Mayor, la conclusión que puede sacarse del análisis de los documentos es que Francesco Pagano, magnífico pintor de frescos de decoración, no fuese capaz de pintar las figuras, cometido éste que fue reservado únicamente a Paolo de San Leocadio. A pesar de esto, sin tener absolutamente en cuenta las citadas fuentes documentales, que constituyen los únicos testimonios de la existencia del maestro napolitano, y sólo sobre la tenue base de un eventual, hipotético, regreso a su ciudad natal después de 1481, se han atribuido a Francesco Pagano algunas pinturas sobre tabla ${ }^{6}$, entre la cuales, en primer lugar, la famosa «Tavola Strozzi» del Museo Nacional de San Martino, en Nápoles, atribución que ha sido demolida recientemente gracias al historiador Mario Del Treppo ${ }^{7}$, quien encontró, en el Archivo de Estado de Florencia, un precioso documento: el libro de cuentas de Filippo Strozzi, en el que está escrito que en 1473, cuando Francesco Pagano se encontraba ya en Valencia, hizo pintar en un taller florentino la cabecera del «lettuccio» (pequeña cama), con la vista de Nápoles, para regalarla a Ferrante de Aragón.

\footnotetext{
${ }^{5}$ Id., op. cit., p. 182. Id., Pintores ..., pp. 180-181.

${ }^{6}$ Ferdinando Bologna, Napoli e le rotte mediterranee della pittura, Nápoles, 1977, pp. 183-201.

${ }^{7}$ Mario del Trepro, Le avventure storiografiche della tavola Strozzi, en Fra storia e storiografia. Scritti in onore di Pasquale Villani, editado por Paolo Macry y Angelo Massafra, Bolonia, 1994, pp. 483-515.
}

$A E A$, LXXVIII, 2005, 310, pp. 175 a 201 
La lectura atenta y la comparación de los documentos del Archivo de la Catedral de Valencia, junto con la ausencia de una obra documentada o firmada, no consienten, razonablemente, que podamos considerar obra de Francesco Pagano las pinturas sobre tabla que se le atribuyen.

Muy diversa habría sido la suerte del maestro napolitano en el caso de que hubiese sido capaz de pintar retablos de la calidad del Trittico dei Sarti, proveniente del Oratorio de San Omobono, actualmente en el Museo de Capodimonte, en Nápoles, que se le atribuye. En Valencia, él habría obtenido un éxito por lo menos comparable al de Paolo de San Leocadio, el cual, una vez acabados los frescos de la Catedral, con sus excelentes pinturas sobre tabla, se convirtió en breve tiempo en el pintor más solicitado por el clero y la aristocracia. Por lo que respecta a Francesco Pagano, de los nueve años transcurridos en Valencia, gracias al mecenazgo de Rodrigo de Borja, ha sido posible reconstruir las atormentadas circunstancias humanas de su vida, pero por lo que toca a su producción artística, podemos solamente imaginar las fastuosas decoraciones que ejecutó sobre las paredes que sostenían la bóveda absidal de la Capilla Mayor de la Catedral de Valencia.

Francesco Pagano, que desde hacía años se vanagloriaba de la protección del cardenal Rodrigo de Borja, debió sufrir una amarga humillación cuando fue reconocida por los canónigos del Capítulo la superioridad del joven Paolo en el representar las imágenes. Esto le impidió participar en la ejecución de los frescos de la bóveda de la Capilla Mayor, ahora descubiertos, que, indudablemente, constituían la parte más prestigiosa de la obra comisionada. En 1481, quizás soportando mal la pérdida del papel de protagonista y la creciente ascensión de la fortuna artística de Paolo de San Leocadio, Francesco Pagano desapareció definitivamente de escena.

Adele Condorelli

\section{UN NUEVO RETRATO ECUESTRE DE CARLOS II, POR HERRERA BARNUEVO *}

En 1667 moría Juan Bautista Martínez del Mazo, yerno de Velázquez, sucediéndole en el puesto de Pintor de Cámara, Sebastián de Herrera Barnuevo que lo ocupará hasta su muerte en 1671. Al acceder a este importante cargo, cuyo cometido fundamental era suministrar la imagen oficial del Monarca reinante, Herrera Barnuevo era ya un artista muy conocido en la Corte, pues desempeñaba el cargo de Maestro Mayor de las Obras Reales desde $1662^{1}$. Será a partir de esa fecha cuando comience a desarrollarse su labor de retratista regio, crean-

* Debo agradecer al profesor Benito Navarrete que me indicara la existencia de este retrato; asimismo, manifiesto mi sincero agradecimiento a los propietarios del cuadro por permitirme el estudio directo del lienzo y por último, al profesor Antonio Martínez Ripoll por ser el artífice de mi interés por estos temas, y por su apoyo y consejo constantes.

${ }^{1}$ Sobre la figura de Sebastián de Herrera Barnuevo y sus actividades véase entre otros, los trabajos de: Whethey, H. E., «Sebastián de Herrera Barnuevo», Anales del Instituto de Arte Americano e Investigaciones Estéticas, II, 1958, pp. 13-41; Whethey, H. E., «Herrera Barnuevo and his Chapel in the Descalzas Reales», Art Bulletin, XLVIII, 1966, pp. 15-34, trabajo que posteriormente apareció traducido al español más resumido con el título de «Herrera Barnuevo y su capilla de las Descalzas Reales», Reales Sitios, 1967, n 13, pp. 12-21; Whethey, H. E., «Decorative Proyects of Sebastian de Herrera Barnuevo», Burlington Magazine, vol 96, 1956, pp. 40-46; Whethey, H. E., «Herrera Barnuevo's Work of the Jesuits of Madrid», Art Quartely, XVII, 1954, pp. 335-344; Cayetano Martín, M. De C., Flores Guerrero, P. y Gallego Rubio, C., «Sebastián de Herrera Barnuevo, Maestro Mayor de las obras de Madrid (1665-1671)», Villa de Madrid, 1989, $\mathrm{n}^{\circ} 27, \mathrm{pp}$ 49-56; y muy recientemente Collar de Cáceres, Fernando, «Notas sobre Sebastián de Herrera Barnuevo, Pintor», Anuario del Departamento de Historia y Teoría del Arte (UAM), vol. XV, 2003, pp. 113-124.

$A E A$, LXXVIII, 2005, 310, pp. 175 a 201 